\title{
Surface Modified Agave sisalana as an Adsorbent for the Removal of Nickel from Aqueous Solutions - Kinetics and Equilibrium Studies
}

\author{
Padmini. E, Helen Kalavathy M. and Lima Rose Miranda^ \\ Dept of Chemical Engineering, A.C.Tech, Anna University, Chennai 600 025, India \\ •e-mail: limamiranda2007@gmail.com \\ (Received March 31, 2008; Accepted May 30, 2008)
}

\begin{abstract}
In the present study Sisal fiber obtained from the leaves of Agave sisalana has been chosen to validate its viability as an adsorbent for the removal of Nickel from aqueous solutions. The material was also surface modified and its effect on adsorption of Nickel was also studied. Agave sisalana fiber was found to be a cheap and effective adsorbent doing away with the need to activate the material therby reducing processing cost. The equilibrium studies indicated that the adsorption capacity of raw fiber and the surface modified fiber was 8.66 and $9.77 \mathrm{mg} / \mathrm{g}$ respectively with the Langmuir isotherm describing the adsorption phenomena better than the Freundlich and Temkin isotherm. The adsorption was found to be exothermic from the thermodynamic studies and the kinetics showed that the adsorption phenomena were second order.
\end{abstract}

Keywords : Sisal fiber, Adsorbent, Nickel, Adsorption, Isotherms, Kinetics, Thermodynamics

\section{Introduction}

Development in the industrial and technology field has resulted in the increase of various problems including threat to the environment and human health due to the release of heavy metal. The release of such metals poses threat because of their toxicity, bioaccumulation in the food chain and persistence in nature.

Possible sources of heavy metal contaminants include sewage and storm water discharges, landfills and cemeteries, incinerators and crematoria, motor vehicles and a range of activities including electroplating, lead smelting, dentists, laboratories timber preservation, drum reconditioning, waste storage and treatment, metal treatment, sheep and cattle dips, scrap metal yards, tanning and chemical manufacturers.

Pure nickel is a hard, silvery-white metal, which has properties that make it very desirable for combining with other metals to form mixtures called alloys. Some of the metals that nickel can be alloyed with are, iron, copper, chromium and zinc. These alloys are used in making metal coins and jewelry and in industry for making items such as valves and heat exchangers. Most nickel is used to make stainless steel. There are also compounds consisting of nickel combined with many other elements, including chlorine, sulfur, and oxygen.

World Health Organization has set guidelines for maximum permissible limit of nickel content in drinking water to be less than $0.1 \mathrm{mg} / \mathrm{L}$. The Ministry of environmental and Forest, Government of India has set minimal national standards of $2 \mathrm{mg} / \mathrm{dm}^{3}$ for safe discharge of effluent containing these metal ions into surface waters. The most common harmful health effect of nickel in humans is an allergic reaction. The most serious harmful health effects from exposure to nickel are chronic bronchitis, reduced lung function, and cancer of the lung and nasal sinus. There are various conventional and non-conventional methods available for the removal of metal from waste water. These methods include Adsorption, Chemical precipitation, Ion exchange, Filtration, Membrane separation and Reverse osmosis.

Chemically modified maize cobs [1], Almond husk [2], Natural zeolite [3], Bagasse fly ash and rice husk ash [4], Oil palm fruit [5], Chitosan derivatives [6] have been examined as a potential adsorbent for the removal of nickel from the aqueous solutions. Since these adsorbents are area specific and/or available in limited quantities has lead to the current study of using sisal fiber as an adsorbent.

Sisal fiber (Agave sisalana species) is obtained from the leaves of this plant. The lustrous strands, usually creamy white, average from 80 to $120 \mathrm{~cm}$ in length and 0.2 to $0.4 \mathrm{~mm}$ in diameter.

Sisal fiber is fairly coarse and inflexible. It is valued for cordage use because of its strength, durability, ability to stretch, affinity for certain dyestuffs, and resistance to deterioration in saltwater. Sisal is used by industry in three grades; the lower grade fiber is processed by the paper industry because of its high content of cellulose and hemicelluloses. The medium grade fiber is used in the cordage industry for making: ropes, baler and binders twine. Ropes and twines are widely employed for marine, 
agricultural, and general industrial use. The higher-grade fiber after treatment is converted into yarns and used by the carpet industry.

The objective of this work is to identify the prospects of using this substance as raw material for the production of adsorbents for removing Nickel by performing adsorption studies on raw sisal fiber and surface modified sisal fiber.

\section{Experimental}

\subsection{Materials and Method}

All the reagents used were of analytical grade and distilled water was used in sample preparation. Nickel sulfate, Dimethyl glyoxime, Hydrochloric Acid, Ammonia were obtained from Ranbaxy Fine Chemicals Ltd., New Delhi. Iodine, Sodium citrate was procured from Ranbaxy Fine Chemicals Ltd., SAS Nagar. Potassium Iodide was procured from Qualigens Fine Chemicals Ltd., Mumbai.

\subsection{Sample solution}

$1000 \mathrm{mg} / \mathrm{L}$ of Nickel stock solution was prepared using Ni $\left(\mathrm{SO}_{4}\right) \cdot 7 \mathrm{H}_{2} \mathrm{O}$. From the stock solution, working solution of $10,20,30$ and $40 \mathrm{mg} / \mathrm{L}$ of solution were prepared by successive dilution.

\subsection{Adsorbent preparation}

\subsubsection{Raw fiber}

The sisal fiber obtained was cut to small pieces of size approximately $15-20 \mathrm{~mm}$. The fiber was thoroughly washed using distilled water and dried completely. Two different types of adsorbent were prepared from the sisal fiber. The fiber, as is, was used to perform the sorption studies.

\subsubsection{Surface modification}

The fiber was soaked in 5\%(by volume) in sodium carbonate for 1 hour. The excess base was decanted and the fiber was then washed with distilled water till the $\mathrm{pH}$ is almost constant and dried in the furnace at $110^{\circ} \mathrm{C}$ till it achieved constant weight [7].

\subsection{Adsorption studies}

Batch adsorption experiments were carried out using raw sisal fiber and surface modified Fiber. The synthetic waste water containing Nickel ions was prepared by dissolving $\mathrm{Ni}$ $\left(\mathrm{SO}_{4}\right) \cdot 7 \mathrm{H}_{2} \mathrm{O}$ in distilled water.

Adsorption experiments were carried out by agitating the adsorbent with $100 \mathrm{~mL}$ of Nickel sulphate solution of desired concentration at particular $\mathrm{pH}$ in a mechanical shaker at a fixed agitation speed of $180 \mathrm{rpm}$. The experiments were carried out for various contact time, different initial Nickel concentration, $\mathrm{pH}$ and temperature.

Samples were withdrawn from the shaker, centrifuged and the supernatant solution was analyzed for residual Nickel concentration.

\subsection{Analytical determination of Nickel ion concentration}

The Nickel ion concentration in the liquid phase was determined spectrophotometrically at a wavelength of $470 \mathrm{~nm}$ against blank by forming complex with Dimethylglyoxime solution.

The amount of adsorbed metal ions per $\mathrm{g}$ of solid is given by

$$
q_{t}=\frac{\left(C_{0}-C_{t}\right) * V}{w}
$$

where $\mathrm{C}_{0}$ is the initial metal ion concentration $(\mathrm{mg} / \mathrm{L}), \mathrm{C}_{\mathrm{t}}$ the metal ion concentration $(\mathrm{mg} / \mathrm{L})$ at any time, $\mathrm{t}, \mathrm{V}$ the volume of the solution $(\mathrm{L})$ and $\mathrm{w}$ is the mass of the adsorbent $(\mathrm{g})$.

\section{Results and discussion}

\subsection{Effect of contact time on percentage adsorption}

The adsorption was carried in a solution containing $30 \mathrm{mg} / \mathrm{L}$ of Nickel solution with the carbon loading of $0.5 \mathrm{~g} / 100 \mathrm{ml}$ solution at $30^{\circ} \mathrm{C}$ and at $\mathrm{pH}$ of 6.3 . Efficiency increased with increase in contact time before the equilibrium was reached. Optimum time for all the type of adsorbents was found to be $240 \mathrm{~min}$. Further increase in contact time did not show a significant change in percentage adsorption. Adsorption was rapid initially and then slower with the passage of time. Initial faster rate of removal is due to the availability of uncovered surface area of the adsorbents, since adsorption kinetics depends on the surface area of the adsorbents [5].

Fig. 1 indicates that the rate of Nickel removal by both

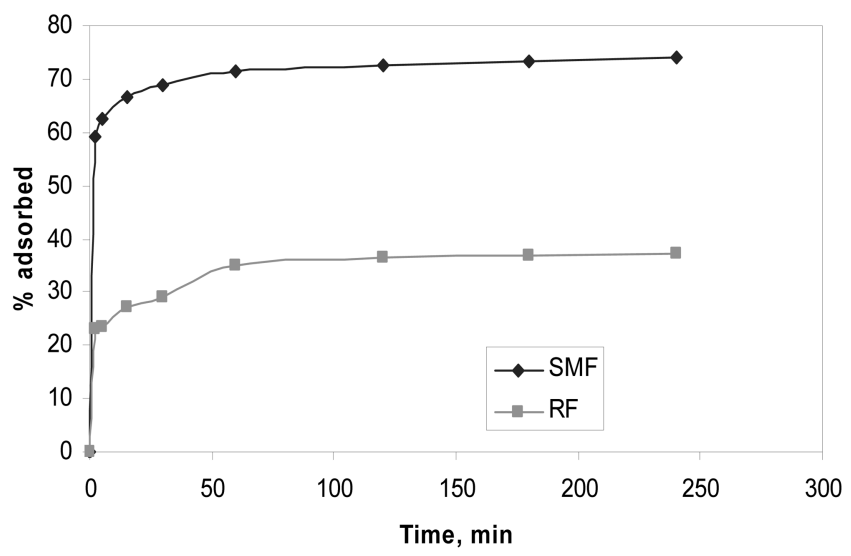

Fig. 1. Effect of contact time on percentage adsorption using SMF and RF. 


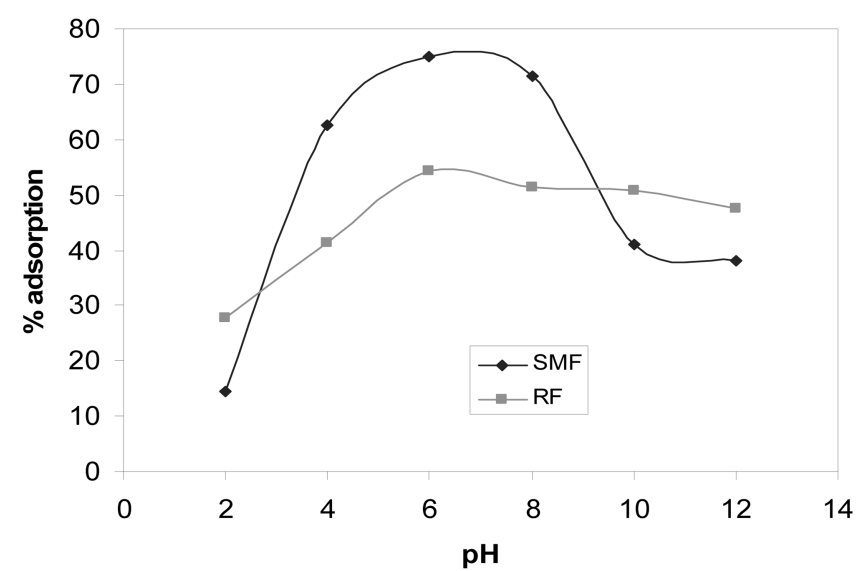

Fig. 2. Effect of $\mathrm{pH}$ on the adsorption of Nickel ion over SMF and RF.

Surface modified (SMF) and raw fiber (RF) followed nearly similar trend. It can be observed that the percentage removal of nickel from the aqueous solution was higher for SMF (74\%) when compared to RF (37\%).

\subsection{Effect of pH on percentage adsorption}

The effect of $\mathrm{pH}$ on adsorption of nickel on SMF and $\mathrm{RF}$ were studied at a temperature of $30^{\circ} \mathrm{C}$ and initial metal ion concentration of $30 \mathrm{mg} / \mathrm{L}$. Various $\mathrm{pH}$ of aqueous solution from 2 to 12 were prepared and the carbon dosage of $0.5 \mathrm{~g} /$ $100 \mathrm{ml}$ of solution was added. Adsorption study was conducted for the equilibrium time of $240 \mathrm{~min}$. The effect is shown in Fig. 2.

Solution $\mathrm{pH}$ is an important factor which dictates the uptake of the metal ion. The Fig. 2 indicates that for both $\mathrm{SMF}$ and $\mathrm{RF}$, the adsorption increases with increase in $\mathrm{pH}$, till a $\mathrm{pH}$ of 6 and after which there is a decrease. At low solution $\mathrm{pH}$, the sorbent surface associates with $\mathrm{H}^{+}$ions which repel the positively charged Nickel ions [8]. As $\mathrm{pH}$ increases the functional group dissociates and becomes negatively charged. Hence more of adsorption at a $\mathrm{pH}$ of 6 and remained almost the same till $\mathrm{pH}$ of 8 . Further increase in the $\mathrm{pH}$ does not contribute to increase in adsorption due to the formation of the soluble hydroxyl group.

\subsection{Effect of initial metal ion concentration on adsorption}

The effect of the initial metal ion concentration was studied at different ion concentration of 10 to $40 \mathrm{mg} / \mathrm{L}$ of Nickel in aqueous solution at a temperature of $30^{\circ} \mathrm{C}$ and adsorbent dosage of $0.5 \mathrm{~g} / 100 \mathrm{~mL}$ of solution. As the solution concentration increases the equilibrium adsorption capacity was found to increase. The equilibrium adsorption capacity for SMF was found to be higher than RF as indicated in Fig. 3. This equilibrium increase could be due to the dispersive force between metal ions and surface of the

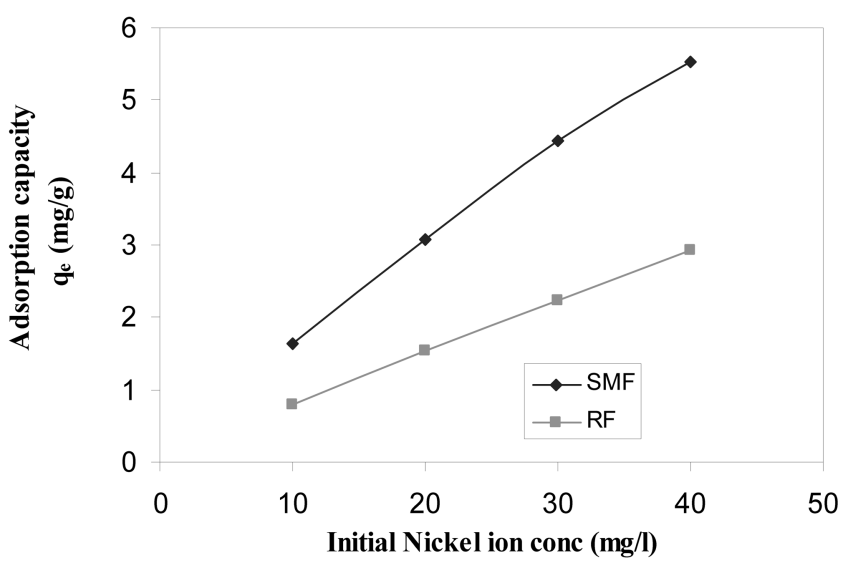

Fig. 3. Effect of initial metal ion concentration over adsorption capacity of the adsorbent.

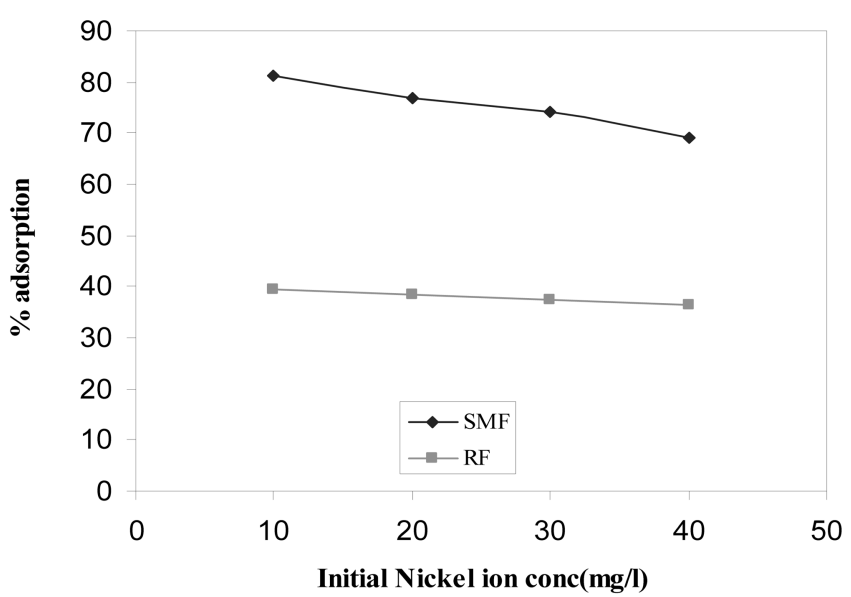

Fig. 4. Effect of initial metal ion concentration over \% adsorption.

adsorbent. As explained by Apipreeya et. al., [9] the attractions between two dipoles are likely to lower the potential energy between them and eventually bring about adsorption.

With regard to the $\%$ adsorption, as the concentration increases the \% adsorption decreases, (Fig. 4), this may be due the non availability of active sites.

\subsection{Effect of Carbon dosage on percentage adsorption}

The adsorbent dosage required for the removal of metal ion was selected by studying, the effect of the carbon dosage on the percentage adsorption. The adsorption studies were conducted using $30 \mathrm{mg} / \mathrm{L}$ initial metal ion concentration and at the temperature of $30^{\circ} \mathrm{C}$. The carbon loading was varied from 0.25 to $1 \mathrm{~g} / 100 \mathrm{~mL}$ of the aqueous solution. The experiment was performed for the equilibration time of $240 \mathrm{~min}$ and at a $\mathrm{pH}$ of 6.3. From Fig. 5 it can be inferred that as the adsorbent dosage is increased for both SMF and $\mathrm{RF}$, the percentage adsorption increases. This is due to the 


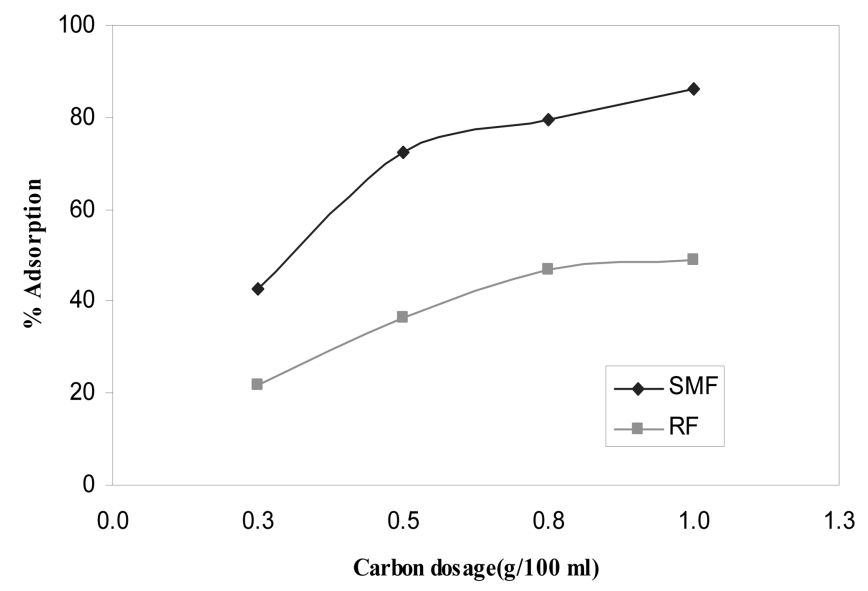

Fig. 5. Effect of adsorbent dosage on percentage adsorption.

fact that more the adsorbent added more is the active sites or more exchangeable groups available for the ion exchange. A maximum of $84 \%$ and $42 \%$ adsorption was achieved for an adsorbent dosage of $1 \mathrm{~g} / 100 \mathrm{~mL}$ of aqueous solution for SMF and RF respectively.

\subsection{Kinetics of Nickel ion adsorption}

Two different kinetic models, namely, pseudo-first-order and pseudo-second-order have been used to test their validity with the experimental adsorption data.

The pseudo first order plot can be obtained from equation 2. The sorption of molecules from a liquid phase to a solid phase can be considered as a reversible process with equilibrium being established between the solution and the solid phase.

The fractional uptake of the adsorbate by the adsorbent can be expressed as

$$
\frac{d q_{t}}{d t}=K_{1}\left[q_{e}-q_{t}\right]
$$

where $\mathrm{q}_{\mathrm{e}}$ is the fraction of the adsorbate adsorbed on the adsorbent under equilibrium condition

$$
\log \left(q_{e}-q_{t}\right)=\log q_{e}-K_{l} t
$$

Eq. (3) is, however, valid only for the initial period of adsorption.

The pseudo-second-order model is based on the assumption of chemisorption of the adsorbate on the adsorbents. This model can be represented in the following form

$$
\frac{d q_{t}}{d t}=K_{2}\left(q_{e}-q_{t}\right)^{2}
$$

where $\mathrm{K}_{2}$ is the pseudo-second-order rate constant $(\mathrm{g} / \mathrm{mg}$ min). The integration of Eq. (4) with the boundary conditions, $\mathrm{q}_{\mathrm{t}}=0$ at $\mathrm{t}=0$ and $\mathrm{q}_{\mathrm{t}}=\mathrm{q}_{\mathrm{t}}$ at $\mathrm{t}=\mathrm{t}$, results in the following equation:

$$
q_{t}=K_{2} q_{e}^{2} t_{1}+K_{2} q_{e} t
$$

Various linearized forms of this equation are possible. The form most often used is given as:

$$
\frac{t}{q_{t}}=\frac{1}{K_{2} q_{e}{ }^{2}}+\frac{1}{q_{e}} t
$$

However, the linear plot between $t / q_{t}$ and $t$ is the so-called ratio correlation in that $\mathrm{t}$ is present in both abscissa and ordinate.

The linearized plot of the pseudo first order (Fig. 6) and pseudo second order (Fig. 7) indicates that the best fit is the pseudo second order kinetics with $\mathrm{q}_{\mathrm{e}}$ calculated to be approximately the same as the experimental values as indicated in Table 1. The rate constants are also determined for both RF and SMF.

\subsection{Adsorption isotherm}

To examine the relationship between sorbed $\left(\mathrm{q}_{\mathrm{e}}\right)$ and aqueous concentration $\mathrm{C}_{\mathrm{e}}$ at equilibrium, sorption isotherm models are widely employed for fitting the data, of which

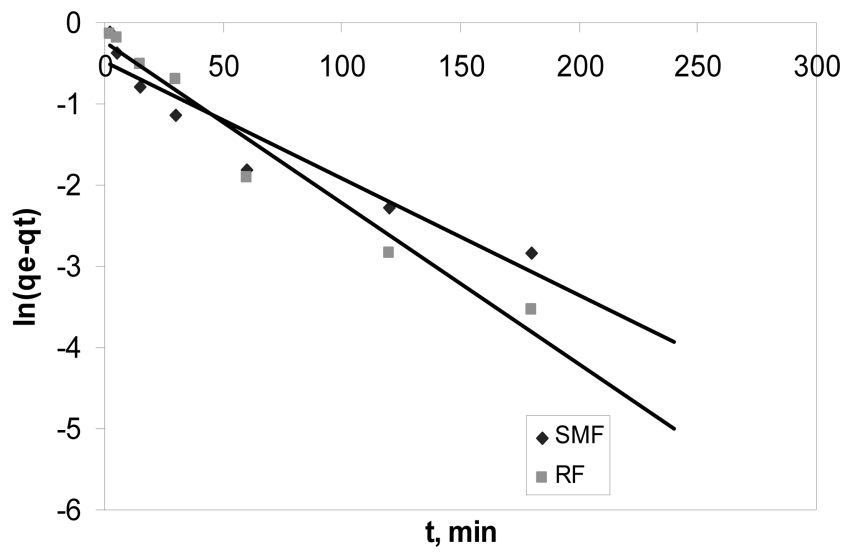

Fig. 6. Pseudo first order kinetics.

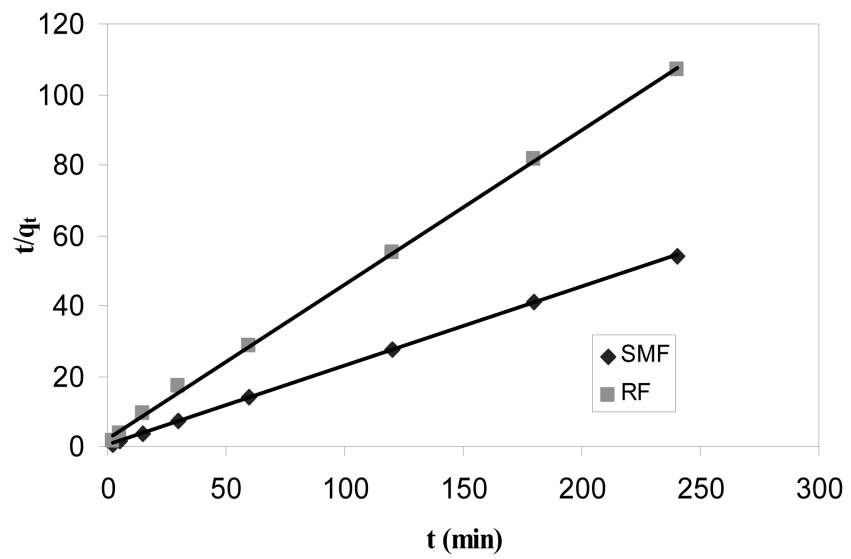

Fig. 7. Pseudo Second order kinetics. 
Table 1. Constants from Pseudo first and second order model

\begin{tabular}{|c|c|c|c|c|c|c|c|}
\hline \multirow[t]{2}{*}{ Adsorbent } & \multicolumn{3}{|c|}{ Pseudo first order } & \multicolumn{3}{|c|}{ Pseudo second order } & \multirow[b]{2}{*}{$\begin{array}{c}\mathrm{q}_{\mathrm{e}}, \\
\text { experiment }\end{array}$} \\
\hline & $\begin{array}{c}\mathrm{q}_{\mathrm{e}} \\
(\mathrm{mg} / \mathrm{g})\end{array}$ & $\begin{array}{c}\mathrm{K}_{1} \\
\left(\min ^{-1}\right)\end{array}$ & $\mathrm{R}^{2}$ & $\begin{array}{c}\mathrm{q}_{\mathrm{e}} \\
(\mathrm{mg} / \mathrm{g})\end{array}$ & $\begin{array}{c}\mathrm{K}_{2} \\
(\mathrm{~g} / \mathrm{mg} / \mathrm{min})\end{array}$ & $\mathrm{R}^{2}$ & \\
\hline RF & 0.795 & 0.0199 & 0.9618 & 2.278 & 0.090 & 0.9993 & 2.243 \\
\hline SMF & 0.614 & 0.0143 & 0.9125 & 4.452 & 0.132 & 0.9999 & 4.449 \\
\hline
\end{tabular}

the Langmuir and Freundlich equations are the most widely used.

The Langmuir model assumes that the uptake of metal ions occurs on a homogenous surface by monolayer adsorption without any interaction between adsorbed ions. The Langmuir model takes the form:

$$
q_{e}=\frac{X_{m} * b^{*} C_{e}}{\left(1+b C_{e}\right)}
$$

where $\mathrm{q}_{\mathrm{e}}(\mathrm{mg} / \mathrm{g})$ is the amount of metal ions adsorbed onto the unit mass of the adsorbent to form a complete monolayer on the surface. $b$ is the Langmuir equilibrium constant which is related to the affinity of binding sites; $\mathrm{C}_{\mathrm{e}}$ the solution phase metal ion concentration. The constants $\mathrm{b}$ and $\mathrm{X}_{\mathrm{m}}$ are the characteristics of the Langmuir equation and can be determined from a linearized form of the Langmuir equation, represented

$$
C_{e} / q_{e}=1 / X_{m} b+C_{e} / X_{m}
$$

Therefore, a plot of $\mathrm{C}_{\mathrm{e}} / \mathrm{q}_{\mathrm{e}}$ versus $\mathrm{C}_{\mathrm{e}}$, gives a straight line of slope $1 / \mathrm{X}_{\mathrm{m}}$ and intercept $1 / \mathrm{X}_{\mathrm{m}} \mathrm{b}$.

On the other hand, the Freundlich equation is an empirical equation based on adsorption on a heterogeneous surface. The equation is commonly represented by

$$
q_{e}=k_{f} C_{e}^{1 / n}
$$

where $k_{f}$ and $\mathrm{n}$ are the Freundlich constants characteristics of the system, indicating the adsorption capacity and the adsorption intensity, respectively. To simplify the derivation of $\mathrm{k}_{\mathrm{f}}$ and $\mathrm{n}$, above equation can be linearized as

$$
\ln q_{e}=\ln k_{f}+1 / n \ln C_{e}
$$

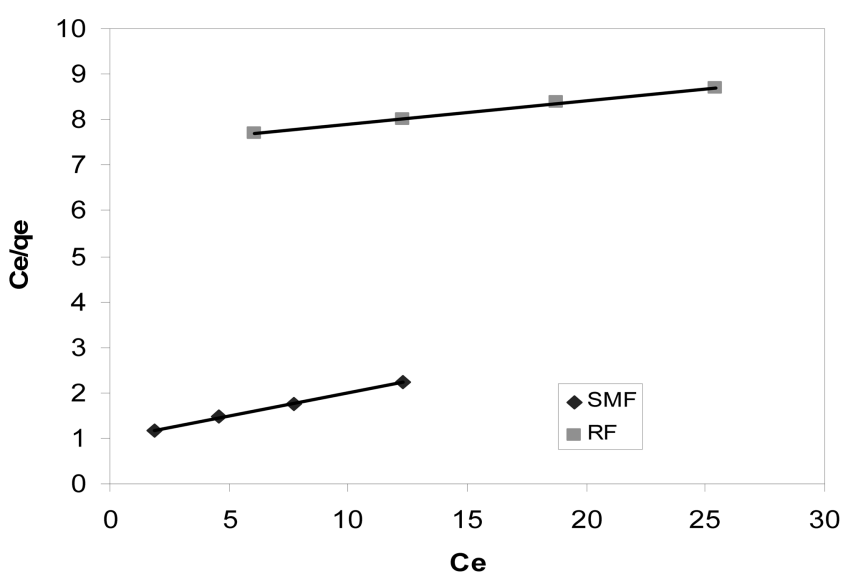

Fig. 8. Langmuir plot for SMF and RF.
Therefore, a plot of $\ln \mathrm{q}_{\mathrm{e}}$ versus $\ln \mathrm{C}_{\mathrm{e}}$ enables the constant $\mathrm{k}_{\mathrm{f}}$ and exponent $\mathrm{n}$ to be determined.

The Temkin isotherm assumes that heat of adsorption of all the molecules in the adsorbed layer decreases linearly with the coverage due to adsorbate-adsorbent interaction and adsorption is characterized by a uniform distribution of binding energies upto a maximum binding energy. The Temkin isotherm has been used in the form as follows:

$$
\mathrm{q}_{\mathrm{e}}=(\mathrm{RT} / \mathrm{b}) \ln \left(\mathrm{A} \mathrm{C}_{\mathrm{e}}\right)
$$

where $\mathrm{RT} / \mathrm{b}=\mathrm{B}$.

The Langmuir, Freundlich and Temkin equations were used to describe the data derived from the adsorption of $\mathrm{Ni}$ by each adsorbent over the entire concentration range studied. The isotherm constants along with their regression

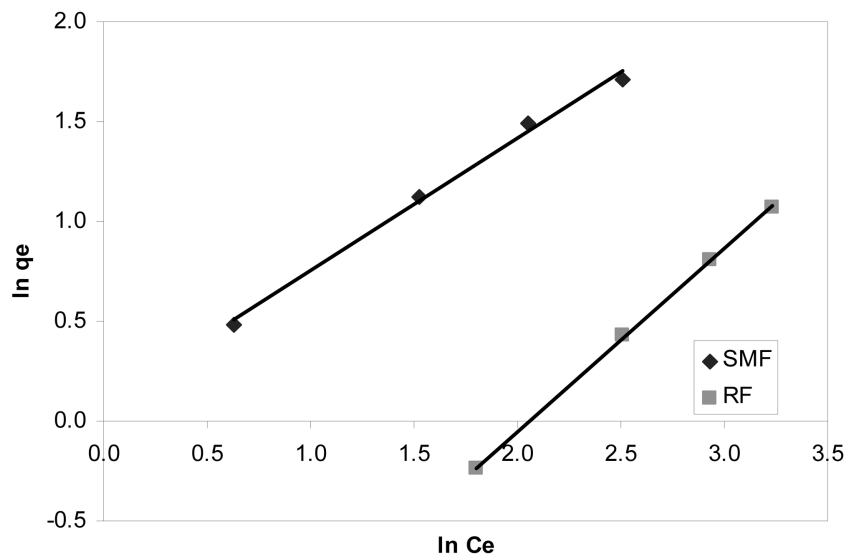

Fig. 9. Freundlich plot for SMF and RF.

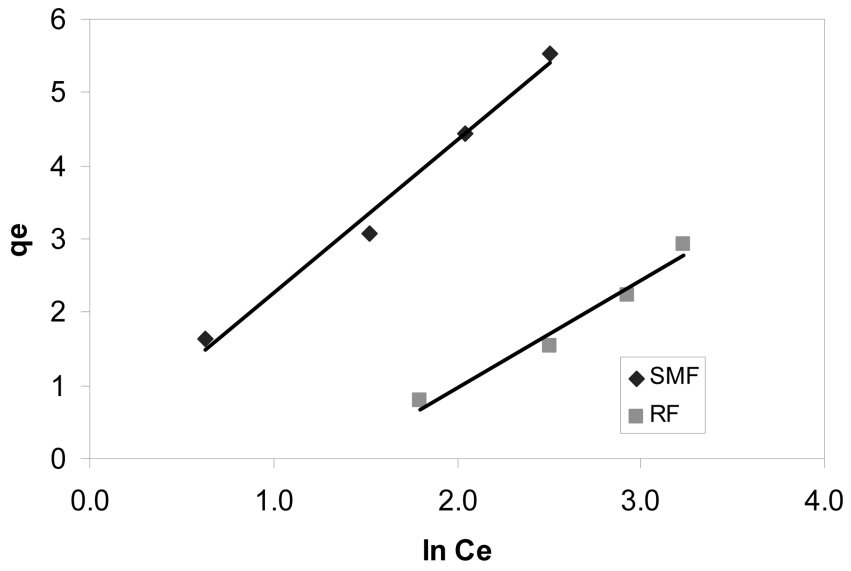

Fig. 10. Temkin plot for SMF and RF. 
Table 2. Langmuir Constants for Raw and surface modified fiber

\begin{tabular}{ccccc}
\hline Adsorbent & \multicolumn{4}{c}{ Langmuir constant } \\
\cline { 2 - 5 } & $\begin{array}{c}\mathrm{X}_{\mathrm{m}} \\
(\mathrm{m} / \mathrm{g})\end{array}$ & $\begin{array}{c}\mathrm{b} \\
(\mathrm{L} / \mathrm{mg})\end{array}$ & $\mathrm{R}^{2}$ & $\mathrm{R}_{\mathrm{L}}$ \\
\hline RF & 8.636 & 0.020 & 0.9992 & 0.621 \\
\hline SMF & 9.970 & 0.102 & 0.9954 & 0.247 \\
\hline
\end{tabular}

Table 3. Freundlich and Temkin Constants for Raw and Surface Modified Fiber

\begin{tabular}{cccccc}
\hline Adsorbent & \multicolumn{3}{c}{ Freundlich constant } & \multicolumn{2}{c}{ Temkin constant } \\
\cline { 2 - 6 } & $\mathrm{n}$ & $\begin{array}{c}\mathrm{K}_{\mathrm{f}} \\
(\mathrm{mg} / \mathrm{g})\end{array}$ & $\mathrm{R}^{2}$ & $\begin{array}{c}\mathrm{b} \\
\mathrm{J} / \mathrm{mol}\end{array}$ & $\mathrm{R}^{2}$ \\
\hline $\mathrm{RF}$ & 1.233 & 0.224 & 0.9997 & 0.725 & 0.9713 \\
\hline SMF & 1.509 & 1.096 & 0.9944 & 0.479 & 0.9872 \\
\hline
\end{tabular}

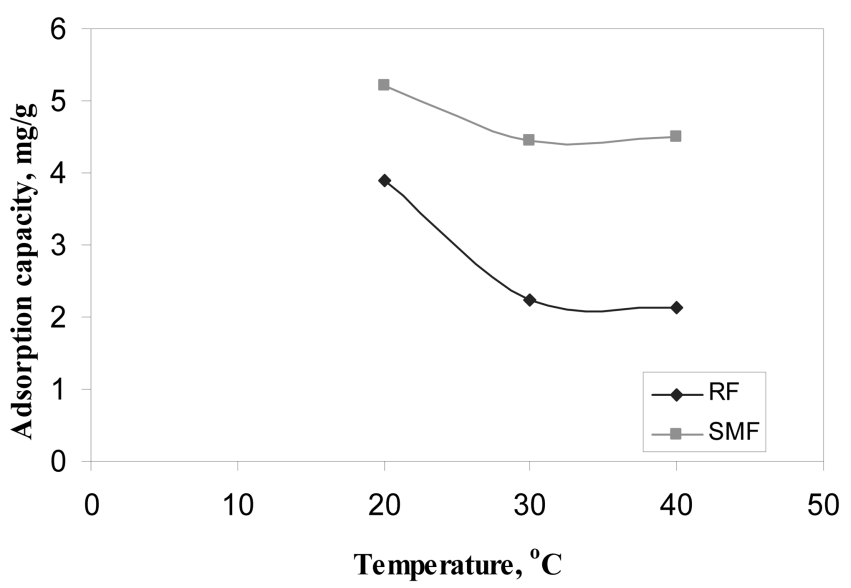

Fig. 11. Effect of temperature on the adsorption capacity of RF and SMF.

coefficient are listed in Table 2 and Table 3. The best fit was found to be Langmuir isotherm with regression coefficient greater than 0.999 and the constants were calculated and indicated in Table 2. The monolayer adsorption capacity for the raw and surface modified obtained from the isotherms and compared with the experimental values.

According to Kadirvelu et.al., (2001), the essential characteristics of Langmuir isotherm can be explained in terms of a dimensionless constant separation factor $\left(\mathrm{R}_{\mathrm{L}}\right)$, defined by:

$$
R_{L}=\frac{1}{\left(1+b C_{o}\right)}
$$

where $\mathrm{b}$ is the Langmuir constant and $\mathrm{C}_{\mathrm{o}}$ is the initial concentration of metal ion. The value of $\mathrm{R}_{\mathrm{L}}$ indicated the type of adsorption to be irreversible $\left(R_{L}=0\right)$, favorable $\left(0<\mathrm{R}_{\mathrm{L}}<1\right)$, linear $\left(\mathrm{R}_{\mathrm{L}}=1\right)$, or unfavorable $\left(\mathrm{R}_{\mathrm{L}}>1\right)$. The $\mathrm{R}_{\mathrm{L}}$ value calculated was found to lie in the favorable region as indicated in the Table 2.

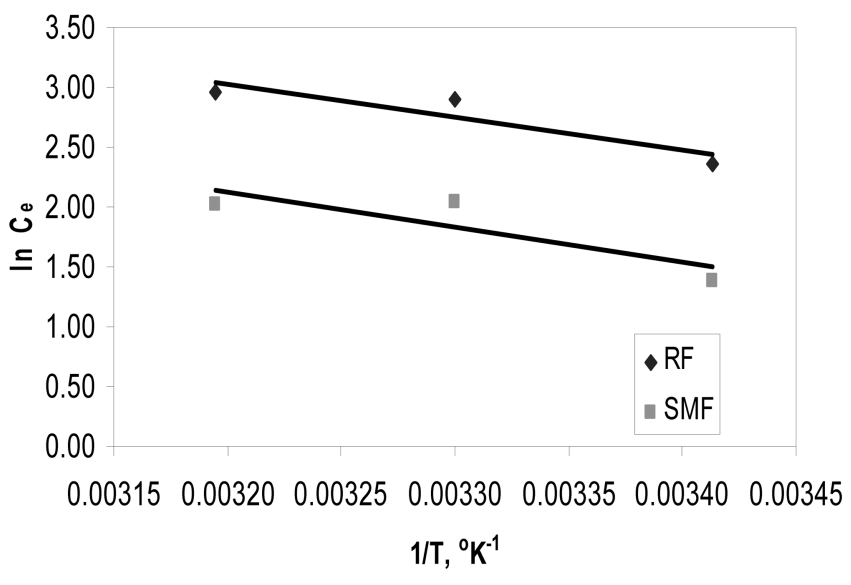

Fig. 12. Evaluation of $\Delta H^{\circ}$ using the plot of $\ln C_{e}$ vs $1 / T$.

\subsection{Effect of Temperature}

The thermodynamic parameters of the adsorption process for the two adsorbents were determined by studying the temperature effect on the adsorption process. The temperature range in which the experiments were carried out was 293 to $313^{\circ} \mathrm{K}$ all other parameters being held constant. Fig. 11 indicates the effect of temperature on the adsorption capacity. As the temperature is increased, the adsorption capacity decreases. The results indicate that the adsorption is favored at low temperature and that the process of adsorption is exothermic in nature [10]. The increase in temperature causes weakening of sorptive forces between the active sites and the metal ions and between the adjacent metal ions adsorbed on the surface of the adsorbent.

\subsection{Thermodynamic studies}

The thermodynamic properties like the change in Gibb's free energy calculated using the Gibb's equation, the change in entropy calculated using Gibb's - Helmholtz equation and change in enthalpy using Clapeyron-Clasius equation.

The value of $\mathrm{H}^{\circ}$ was calculated using Clapeyron-Clasius equation

$$
\operatorname{In} C_{e}=K+\frac{\Delta \mathrm{H}^{\mathrm{o}}}{R T}
$$

where $\mathrm{C}_{\mathrm{e}}(\mathrm{mg} / \mathrm{L})$ is the equilibrium concentration of adsorbate in solution corresponding to a specified equilibrium amount adsorbed onto adsorbent, $\mathrm{R}$ the universal gas constant $(8.314 \mathrm{~J} / \mathrm{mol} \mathrm{K})$, the thermodynamic constant, $\Delta \mathrm{H}^{\circ}$ the change in enthalpy $(\mathrm{J} / \mathrm{mol}) . \Delta \mathrm{H}^{\circ}$ was determined by plotting $\ln \mathrm{C}_{\mathrm{e}}$ as function of $1 / \mathrm{T}$. The plot of $\ln \mathrm{C}_{\mathrm{e}}$ as a function of $1 / \mathrm{T}$ for both the adsorbent showed that the value of $\Delta \mathrm{H}^{\circ}$ to be negative indicating that the adsorption process is exothermic. The value of $\Delta \mathrm{H}^{\circ}$ for $\mathrm{RF}$ and $\mathrm{SMF}$ was calculated to be $-2810 \mathrm{~J} / \mathrm{mol}$ and $-2930 \mathrm{~J} / \mathrm{mol}$ respectively. 


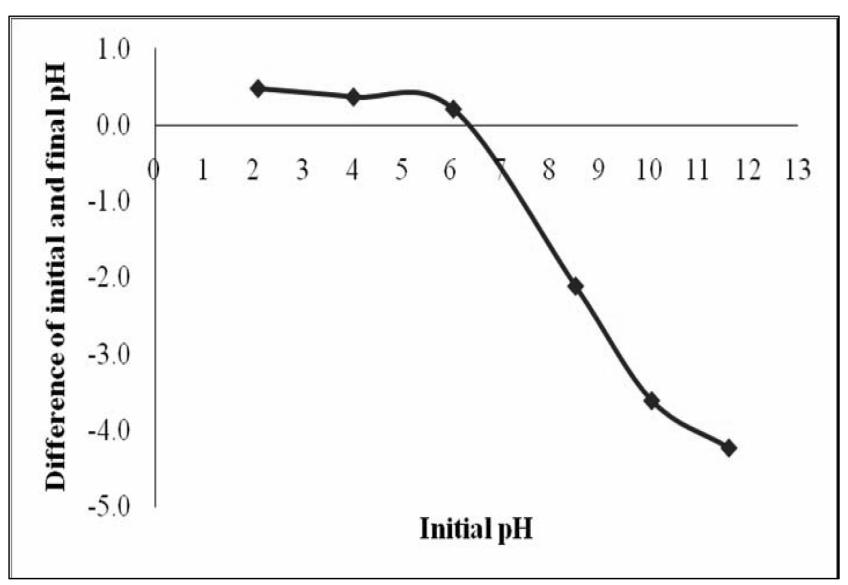

Fig. 13. Determination of Zeta Potential for RF.

Using Gibb's free energy equation $\Delta \mathrm{G}^{\mathrm{o}}$ was calculated as

$$
\Delta G^{o}=-R T \operatorname{In} K c
$$

where $\mathrm{K}_{\mathrm{c}}$ is the thermodynamic equilibrium constant. The $\Delta \mathrm{G}^{\mathrm{o}}$ value was determined using equation 13 and was found to be negative for both adsorbent. As temperature increases, the value of $\Delta \mathrm{G}^{\circ}$ increases and in the order of $1.45 \mathrm{~kJ} / \mathrm{mol}$. Negative value of $\Delta \mathrm{G}^{\mathrm{o}}$ indicates that the adsorption process was spontaneous.

The change in entropy $\Delta S^{\circ}$ was calculated according to the Gibb's Helmholtz equation

$$
\Delta S^{o}=\frac{\Delta H^{o}-\Delta G^{o}}{T}
$$

The value of $\Delta S^{\circ}$ was calculated and found to be negative for both RF and SMF. This indicates that the adsorption process is more ordered when the adsorbates were adsorbed on to the adsorbents.

\subsection{Determination of $\mathrm{pH}_{p z c}$ ( $\mathrm{pH}$ point of zero charge or Zeta Potential)}

The determination of the $\mathrm{pH}_{\mathrm{pzc}}$ of the samples was carried out using standard procedure. The $\mathrm{pH}_{\mathrm{pzc}}$ is a point at which the surface acidic (or basic) functional groups no longer contribute to the $\mathrm{pH}$ value of the solution [11]. It was found to be at $\mathrm{pH}$ value of 6.3. There exists a relationship between $\mathrm{pH}_{\mathrm{pzc}}$ and adsorption capacity, cation adsorption on any adsorbents will be favourable at $\mathrm{pH}$ value higher than $\mathrm{pH}_{\mathrm{pzc}}$. While anions adsorption will be favoured at $\mathrm{pH}$ values lower than $\mathrm{pH}_{\mathrm{pzc}}$.

\subsection{SEM analysis}

Fig. 14(a) and (b) shows the Scanning electron micrographic images at 500 magnifications of raw fiber and surface modified fiber which shows the surface of the fibers. Surface is more homogeneous in the case of surface modified fiber in comparison to raw fiber which shows a more heterogeneous surface.

\section{Conclusion}

Sisal fiber obtained from the leaves of Agave sisalana and extensively found in the southern regions of India has been found to be a potential adsorbent for the removal of Nickel. Surface modification using Sodium carbonate has been observed to increase the adsorption capacity of the adsorbent.

The equilibrium studies indicated that the adsorption phenomenon could be well explained by the Langmuir isotherm and that the kinetics was second order.

The process was considered to be exothermic and spontaneous from the values of $\Delta \mathrm{H}^{\circ}$ and $\Delta \mathrm{G}^{\circ}$. Thus, sisal fiber can be considered to be a cheap and viable adsorbent for the removal of Nickel from the aqueous solution.

\section{Nomenclature}

b Langmuir constant related to adsorption energy $(\mathrm{L} / \mathrm{mg})$ C Concentration of adsorbate at time $\mathrm{t}(\mathrm{mg} / \mathrm{L})$

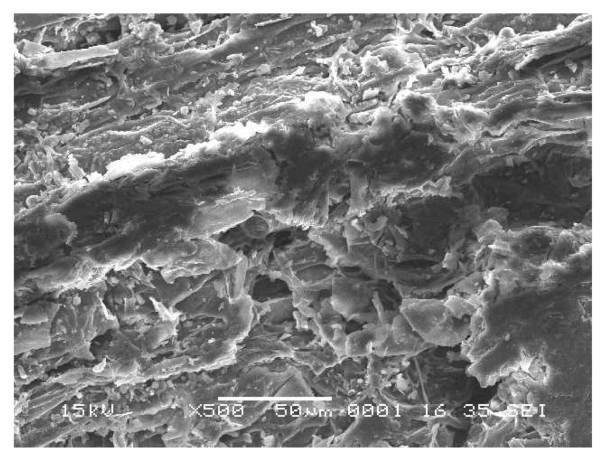

(a)

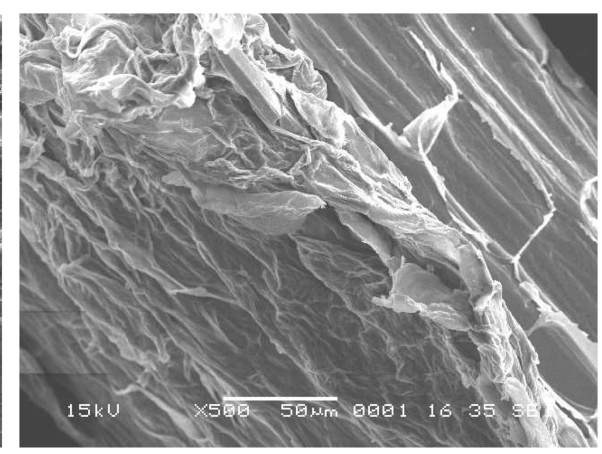

(b)

Fig. 14. SEM image of raw sisal fiber(a) and modified fiber(b). 
$\mathrm{C}_{\mathrm{e}} \quad$ Equilibrium concentration of adsorbate $(\mathrm{mg} / \mathrm{L})$

$\mathrm{C}_{\mathrm{o}} \quad$ Initial concentration of adsorbate $(\mathrm{mg} / \mathrm{L})$

$\mathrm{K}_{1}$ the rate constant of pseudo first-order adsorption (min-1)

$\mathrm{K}_{2}$ the rate constant of pseudo second-order adsorption ( $\mathrm{g} / \mathrm{mg} / \mathrm{min}$ )

$\mathrm{K}_{\mathrm{f}} \quad$ Freundlich constant indicating adsorption capacity $(\mathrm{mg} / \mathrm{g})$

n Freundlich constant indicating adsorption intensity

$\mathrm{q}_{\mathrm{e}} \quad$ Amount of adsorbate adsorbed at equilibrium (mg/g)

$\mathrm{X}_{\mathrm{m}} \quad$ Langmuir constant related to the adsorption capacity of adsorbent $(\mathrm{mg} / \mathrm{g})$

$\mathrm{R} \quad$ universal gas constant $(\mathrm{J} / \mathrm{mol} / \mathrm{K})$

$\mathrm{R}^{2} \quad$ correlation coefficient

$\mathrm{t}$ time (min)

$\mathrm{T}$ absolute temperature $(\mathrm{K})$

$\mathrm{G}^{\mathrm{o}} \quad$ free energy change $(\mathrm{J} / \mathrm{mol})$

$\mathrm{H}^{\mathrm{o}} \quad$ enthalpy change $(\mathrm{J} / \mathrm{mol})$

$\mathrm{S}^{\mathrm{o}} \quad$ entropy change $(\mathrm{J} / \mathrm{mol} / \mathrm{K})$

RF Raw sisal Fiber

SMF Surface Modified sisal fiber

SEM Scanning electron micrograph

\section{References}

[1] Akporhonr, E. E.; Egwaikhide, P. A. International Journal of Applied Environmental Sciences 2007, 2, 132.

[2] Hasar, H. Journal of Hazardous Materials 2003, 97, 49.

[3] Peri, J.; Trgo, M.; Vukojevi, N.; Medvidovi. Water Research 2004, 38, 1893.

[4] Srivastava, V. C.; Mall, I. D.; Mishra, I. M.; Chemical Engineering Journal 2007, 132, 267.

[5] Abia, A. A.; Asuquo, E. D, African Journal of Biotechnology 2006, 5, 1475.

[6] Becker, T.; Schlaak, M.; Strasdeit, H.; Reactive and Functional Polymers 2000, 44, 289.

[7] Ewecharoen, A.; Thiravetyan, P.; Nakbanpote, W. Chemical Engineering Journal 2008, 137, 181.

[8] Ofomaja, A. E.; Ho, Y. S. Bioresource Technology 2007, 99, 5411.

[9] Apipreeya, K., Carbon 2007, 6, 1132

[10] Stephen Inbaraj, B.; Chiu, C. P.; Ho, G. H.; Yang, J.; Chen, B. H. Bioresource Technology 2008, 99, 1026.

[11] Saifuddin, M. N.; Kumaran, P. Electronic Journal of Biotechnology 2005, 8, 43 